\title{
ESTIMATION OF AM FUNGAL COLONIZATION - COMPARABILITY AND RELIABILITY OF CLASSICAL METHODS
}

\author{
ANNA FÜZY*, IBOLYA BIRÓ, RAMÓNA KovÁCS and TÜNDE TAKÁCS* \\ Hungarian Academy of Sciences, Centre for Agricultural Research, \\ Institute for Soil Sciences and Agricultural Chemistry, Budapest, Hungary
}

(Received: 31 July 2015; accepted: 19 September 2015)

\begin{abstract}
The characterization of mycorrhizal status in hosts can be a good indicator of symbiotic associations in inoculation experiments or in ecological research. The most common microscopic-based observation methods, such as (i) the gridline intersect method, (ii) the magnified intersections method and (iii) the five-class system of Trouvelot were tested to find the most simple, easily executable, effective and objective ones and their appropriate parameters for characterization of mycorrhizal status. In a pot experiment, white clover (Trifolium repens L.) host plant was inoculated with Glomus intraradices (BEG144; syn. Rhizophagus intradices) in pumice substrate to monitor the AMF colonization properties during host growth. Eleven (seven classical and four new) colonization parameters were estimated by three researchers in twelve sampling times during plant growth. Variations among methods, observers, parallels, or individual plants were determined and analysed to select the most appropriate parameters and sampling times for monitoring. The comparability of the parameters of the three methods was also tested. As a result of the experiment classical parameters were selected for hyphal colonization: colonization frequency in the first stage or colonization density in the later period, and arbuscular richness of roots. A new parameter was recommended to determine vesicule and spore content of colonized roots at later stages of symbiosis.
\end{abstract}

Keywords: arbuscular mycorrhizal fungi (AMF), monitoring, root colonization parameters

\section{Introduction}

Arbuscular mycorrhizal fungi (AMF) (phylum Glomeromycota), as the most abundant and ancient symbiotic partners of about $80-90 \%$ of the higher plants $[1,2]$, are essential components of different terrestrial ecosystems [3, 4].

\footnotetext{
*Corresponding authors; E-mails: fuzy@rissac.hu; takacs@rissac.hu
} 
AM fungi are known to promote vitality and fitness of hosts by increased plant mineral nutrition, especially $P$ acquisition [5], enhanced water supply [6] and by providing resistance to abiotic or biotic environmental stress conditions [7-10].

The mycorrhizal status of plant species in agricultural or natural ecosystems could be a good assay for soil health and ecosystem stability. The presence of AMF specific structures, such as arbuscules and vesicules in colonized roots can indicate not only the symbiotic phase of fungal life cycle but also the host/ non-host discrimination [11]. Furthermore, the investigation of colonized root segments in relation to root density of host plant could be a suitable test for estimating the number of infective AMF propagules of indigenous fungi in soil. In recent years much attention has been paid to large-scale production and to the research of the applicability of AMF as bioprotectors or biofertilizators [12] either in agricultural management, forestry and natural ecosystems. Quality control with continuous monitoring based on investigation of colonization properties must be part of a high quality inoculum production process [13].

Microscopic investigation of stained root samples is still the most popular and simplest way to determine AMF colonization rate [14]. Numerous techniques for clearing and vital or non-vital staining of AMF colonized roots have been published. The major part of methods investigating AMF root colonization is destructive and does not supply information about functional aspect of symbiotic association $[15,16]$. Current staining techniques and observation methods are as follows: staining with tryphan blue [17], acid fuchsin [18, 19], chlorazol black [20] or cotton blue [21] after clearing of the root sample in $\mathrm{KOH}$, post-fixation could be done in lactic acid. The methods for estimation of fungal colonization are based on the detection of AMF-specific key structures in colonized roots [19, 22-33].

The most commonly used estimation methods to determine the colonization rate are the gridline intersect method [25], the magnified intersections method [28] and the five-class system of Trouvelot et al. [33]. More than 150 articles were checked for methods that had been used for quantification of mycorrhizal status in host roots, $37 \%, 22 \%$ and $17 \%$ of the scientific works applied one of the previous three methods, respectively. It is also worth considering that implementation should be easy and the least-toxic chemicals should be used, when we are going to find the most suitable method.

In our study we investigated how effectively and relevantly the well-known and some new parameters describe the temporal changes of mycorrhizal status during the life-cycle of Glomus intradices (BEG144; syn. Rhyzophagus intraradices) using white clover host. 


\section{Materials and Methods}

\section{Experimental design}

A pot experiment was established to hold up to model the AM-symbiosis and fungal life cycle. White clover (Trifolium repens L.) as test plant was grown in pumice substrate $(500 \mathrm{~g}$ per pot). Pumice is a rhiolite tuff with a vitroclastic texture which has the following characteristics: $\mathrm{pH}_{(\mathrm{H} 2 \mathrm{O})}: 6.63$; humus content: 0.094\%; AL-K 2 O: 259 mg kg-1; AL- $\mathrm{P}_{2} \mathrm{O}_{5}: 19.5 \mathrm{mg} \mathrm{kg}{ }^{-1} ; \mathrm{NH}_{4}-\mathrm{N}: 3.16 \mathrm{mg} \mathrm{kg}^{-1}$; $\mathrm{NO}_{3}-\mathrm{N}: 1.16 \mathrm{mg} \mathrm{kg}^{-1}$; KCl-Mg: $40.5 \mathrm{mg} \mathrm{kg}^{-1}$ and water storage capacity $90 \%$. Horticulture often uses it as growing substrate in hydrocultures.

Rhizophagus intraradices BEG 144 (Glomus intraradices, Schenck and Smith) was used as inoculum, it is one of the most common AMF species in the fungal communities of different ecosystems [34]. The AMF inoculum (2\%) was stratified in the rooting zone (in one layer). White clover was grown in a growth chamber under controlled light and temperature conditions (temperature between 25 and $17^{\circ} \mathrm{C} ; 16 / 8$ hours light (25,000 lux)/dark period). $150 \mathrm{ml}$ of nutrient solution was added to the plants once a week (phosphorus poor Hoagland solution; $0.2 \mathrm{mM} \mathrm{KH}_{2} \mathrm{PO}_{4}$ ).

\section{Root samples}

Root colonization was monitored weekly from the second week through 3 months (13 weeks):

(1) Three plants were removed from one pot, and three subsamples were formed to check the variation from plant to plant by the Trouvelot method [33], (one pot weekly).

(2) Three plants were removed from three pots each (replicates), and root samples were collected for microscopic investigation with three methods: (i) the gridline intersect method [25], (ii) the magnified intersections method [28] and (iii) the five-class system of Trouvelot [33], and by three observers (3 pots weekly).

(3) Whole root system of one plant was observed in the first five weeks to track the process of the early colonization (one plant weekly).

\section{Classical and new parameters for AM status characterization}

Root samples were cleared in $\mathrm{KOH}$, stained in aniline-blue and fixed in lactic acid. The classical parameters of these methods and some new parameters 


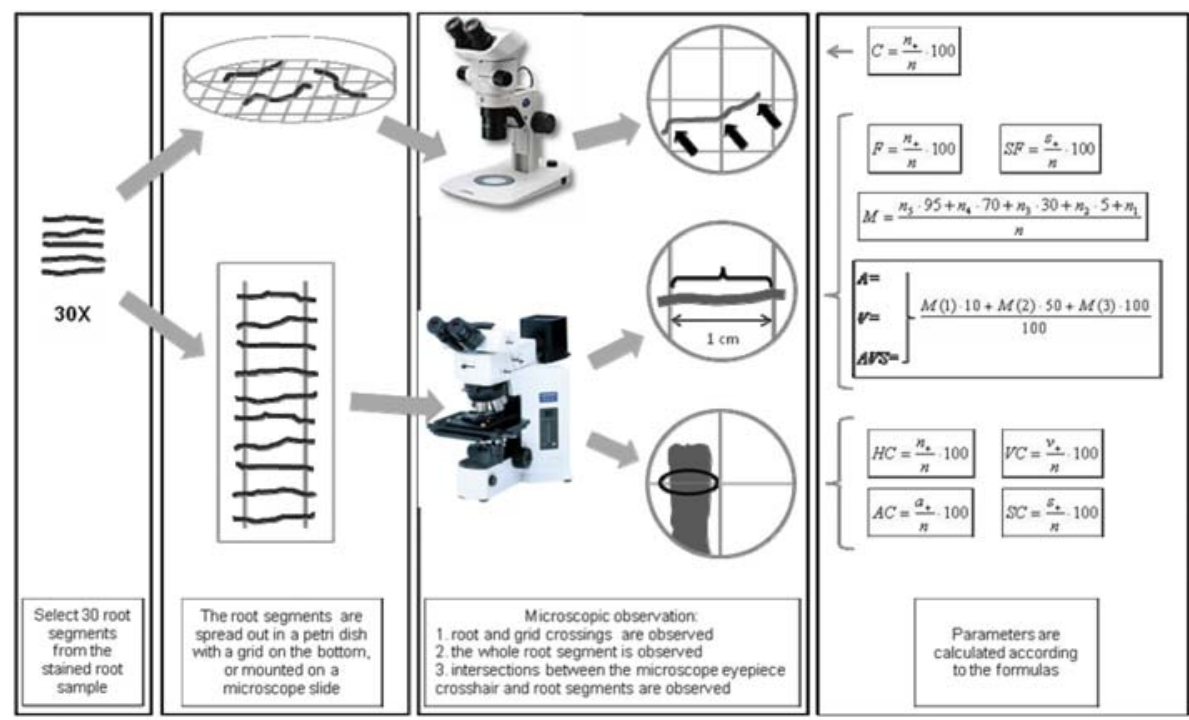

Figure 1. Schematic figure of root observation and parameter calculation, n: number of observed root segments/crossings/intersections, $\mathrm{n}_{+}$: colonization positive root segments/crossings/intersections, $\mathrm{a}_{+}$: arbusculum positive root intersections, $\mathrm{v}_{+}$: vesiculum positive root intersections, $\mathrm{s}_{+}$: spore positive root segments/intersections, $\mathrm{n}_{1-5}$ : number of root segments in the five classes of Trouvelot, $\mathrm{M}(1), \mathrm{M}(2)$,

M(3): M values calculated with high (3), medium (2) and low (1) level classes of different fungal structures (A: arbuscules, V: vesicules, AVS: arbuscules, vesicules and spores) in Trouvelot method

were tested during the experiment. All parameters are measured as a percentage value representing the proportion of the root system, number of root pieces or root crossings that were colonized: (1) the colonization rate $(\mathrm{C})$ with the gridline intersect method, (2) F (colonization frequency), (3) M (intensity of colonization), (4) A (absolute arbuscule richness) according to the five-class system of Trouvelot et al. [33]. The developed parameters were assessed according to the measurement procedure of the original method. (5) SF (spore frequency), according to the presence or absence of the spores in the root segment, (6) V (vesicule richness), as described in case of arbuscular structures in the five-class system and (7) AVS (AVS richness) to estimate the collective appearance of arbuscules, vesicules and spore structures with the technique of the five-class system. The (8) AC (arbuscular colonization), the (9) VC (vesicular colonization) and (10) HC (hyphal colonization) were determined with the magnified intersections method. The (11) spore colonization (SC) was also measured, as a new parameter with the same method. These 11 colonization parameters were determined by three observers in 12 sampling time during the propagation process. Olympus B071 stereoscopic dissecting microscope (40-60x magnification) was used for the gridline method 
Table I. AMF colonization distribution in the first five weeks in the white clover (Trifolium repens L.) root system

\begin{tabular}{lll}
\hline Layers in the pot & Root ramification & AMF colonization \\
\hline above inoculums & $\begin{array}{l}\text { Colonization spreads over from the inoculum layer after } \\
\text { the 3rd week }\end{array}$ \\
inoculums & $\begin{array}{l}\text { Light colonization for the 2nd week with 1-2 entry points, } \\
\text { heavy colonization from the 3rd week }\end{array}$ \\
bottom & $\begin{array}{l}\text { Spreading of colonization starts on the 3rd week, } \\
\text { no heavy colonization until the 4th-5th week }\end{array}$ \\
Colonization starts to spread from 1-2 entry point after \\
the 3rd week
\end{tabular}

and Olympus BX51 light microscope (100-200x) was used for the other two methods.

Thirty root segments each about $1 \mathrm{~cm}$ long were removed from the samples and used for each method to eliminate the sampling error: first, these root segments were spread out in a Petri dish and the gridline intersect method was used to determine the $\mathrm{C}$ value. The root segments were mounted on microscope slides and the magnified intersections method (HC, AC, VC, SC) and the Trouvelot method (F, M, A, V, AVS, SF) was used to determine the colonization parameters. The time spent to calculate each parameter was also measured to determine the effort of these methods (Figure 1).

\section{Data analysis}

Percentage values of colonization data sets were analysed, mean value (MV) and standard deviation (SD) of parallels and observers were calculated.

\section{Results}

\section{Sampling}

The variation derived from the sampling method was tested by parallel plots, subsamples and also by repeating the root segment selection from the stained sample. The staining and the observation of the total root system also give information on the distribution and the spreading of the symbiotic connection in the early colonization period which promotes the determination of the adequate sampling time (Table I). 
Table II. Mean value and standard deviation (SD)

of some possible error sources during sampling and observing at $\mathrm{F} \%, \mathrm{M} \%, \mathrm{~A} \%$ and $\mathrm{V} \%$ parameters calculated by the Trouvelot et al. [33] method on the $5^{\text {th }}$ week

\begin{tabular}{|c|c|c|c|c|c|c|}
\hline & & & F & M & A & V \\
\hline \multirow{2}{*}{$\begin{array}{l}\text { Mean value and standard } \\
\text { deviation of parallels }\end{array}$} & \multirow{2}{*}{$\begin{array}{l}\text { mixed root segments of three } \\
\text { individual plants from three } \\
\text { different pots }\end{array}$} & mean & 76.67 & 61.61 & 51.68 & 36.74 \\
\hline & & SD & 3.34 & 8.73 & 9.41 & 9.81 \\
\hline \multirow[t]{2}{*}{$\begin{array}{l}\text { Mean value and standard } \\
\text { deviation of observers }\end{array}$} & \multirow{2}{*}{$\begin{array}{l}\text { estimation of the colonization } \\
\text { parameters from the same } 30 \\
\text { root segments by } 3 \text { different } \\
\text { observers }\end{array}$} & mean & 80.00 & 66.31 & 53.79 & 35.35 \\
\hline & & SD & 3.33 & 3.12 & 6.16 & 16.45 \\
\hline \multirow{2}{*}{$\begin{array}{l}\text { Mean value and standard } \\
\text { deviation of individual } \\
\text { plants }\end{array}$} & \multirow{2}{*}{$\begin{array}{l}\text { mixed root segments of three } \\
\text { different individual plants } \\
\text { from the same pot }\end{array}$} & mean & 100.00 & 90.06 & 83.62 & 41.51 \\
\hline & & SD & 0.00 & 3.95 & 6.02 & 11.81 \\
\hline \multirow{2}{*}{$\begin{array}{l}\text { Mean value and standard } \\
\text { deviation of root } \\
\text { segment selection }\end{array}$} & \multirow{2}{*}{$\begin{array}{l}\text { three different selection of } 30 \\
\text { root segments from the same } \\
\text { stained root sample }\end{array}$} & mean & 86.55 & 78.46 & 66.88 & 48.12 \\
\hline & & SD & 8.75 & 11.53 & 8.73 & 5.40 \\
\hline
\end{tabular}

Tables I and II show some of the possible sources of errors: (1) Uneven distribution of AMF root colonization appears during the first weeks: high colonization is shown in the inoculum layer, lower rate of colonization is found at the top and the bottom region of the root, almost no colonization is detected at the middle part of the root system, where ramification is lower, but root grows very fast. (2) In the same pots the AMF root colonization can change from plant to plant, even in similar microenvironment. Standard deviation of root colonization measured in subsamples was found similar to the SD of parallel values. (3) Standard deviation values in the table suggest that the sample selection from the stained root preparation can be a serious source of error, as well. (4) Observer subjectivity depends on the applied methods and parameters. However, the assessment of the colonization values was much less dependent on the personality of the observer than the recognition of some fungal structures that determines other parameters.

\section{Colonization rate}

The colonization rate - percentage of roots colonized by arbuscular mycorrhizal fungi - is estimated by three parameters according to the three methods (Figure 2a). The colonization percentage (C; M; HC) significantly increased during the first four weeks. $70-80 \%$ of the root system was colonized by the 

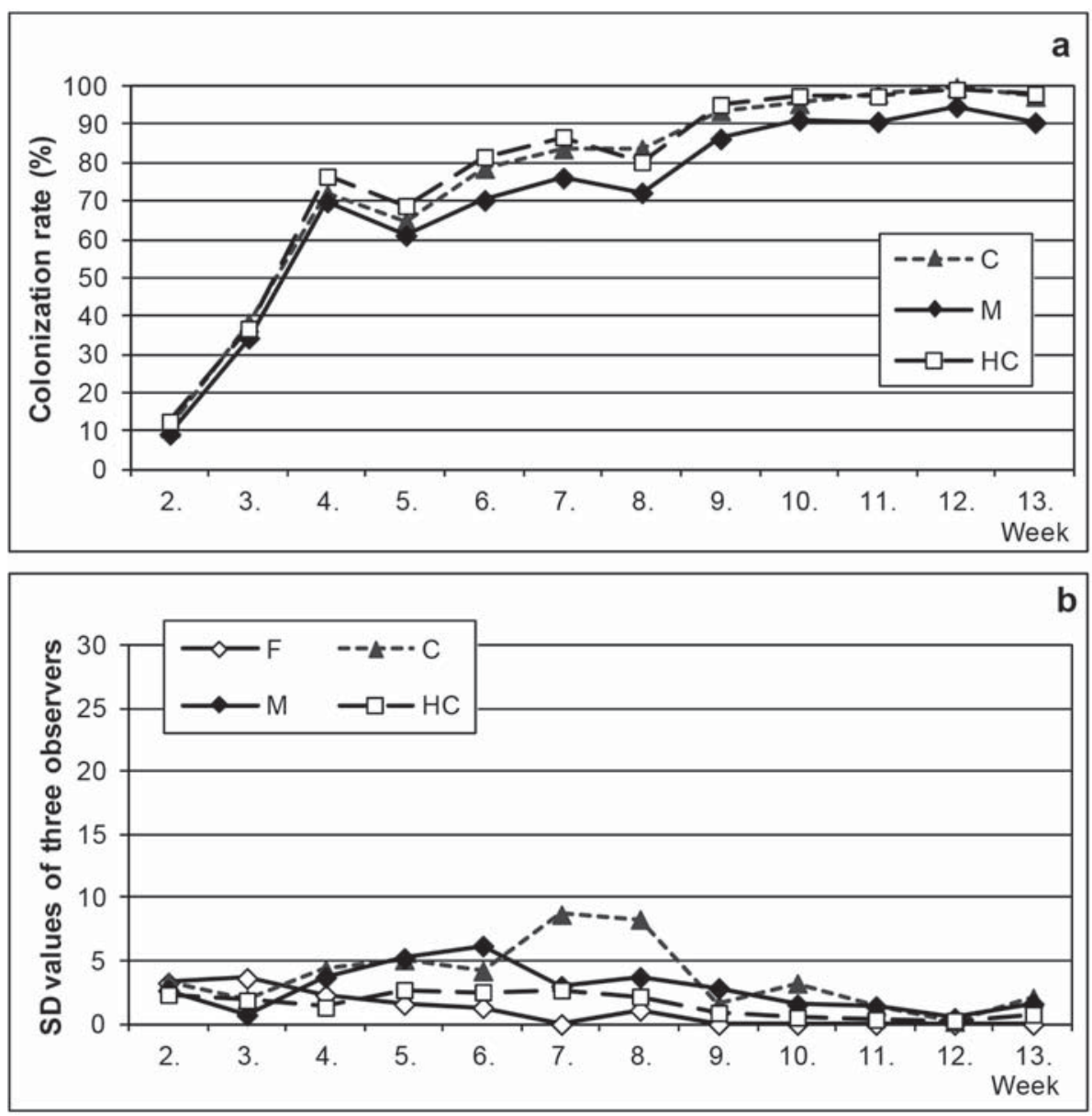

Figure 2. Colonization rate and standard deviation of the root system estimated by three different methods during the propagation process, a: mean values of three parallels and three observers, b: standard deviation (SD) among the three observers during the 3 months

(C: according to the grid-intersect method HC: according to the magnified intersections method M: according to the five-class system of Trouvelot, F: colonization frequency according to the five-class system of Trouvelot)

$4^{\text {th }}$ week, from the $4^{\text {th }}$ week the colonization converged slowly to the maximum value with a light fluctuation.

The average variation among methods (variation calculated each week among the three parameters $-\mathrm{C}, \mathrm{M}, \mathrm{HC}$ ) was 3.9. This low value indicates that all methods, independently of the way they calculate the percentage of colonized root segments, approximate the real value similarly well. The variation was also 
consistent, the Trouvelot method resulted always in a lower estimation, while the other two methods gave nearly the same values every week. The difference between the Trouvelot method and the two other methods became higher from the $6^{\text {th }}$ week, when the rate of fully colonized root segments exceeded $50 \%$. The $5^{\text {th }}$ class in Trouvelot method represented $95 \%$ colonization, which can result in underestimation, in case of fully colonized $(100 \%)$ root segments.

The time requirement of the methods and the observer's dependency of the parameters is shown in Table III. The higher variance in the gridline intersect method was caused by the movement of the roots above the grid in the glycerine, therefore the crossing was not the same for all observers. The magnified intersections method and the Trouvelot method use a fixed preparatum with fix crossing sites, when observer's dependency derives mainly from the researchers' decision about the AMF structures. The standard deviation of the different observers' results is about two times higher in case of the Trouvelot method, but still the maximum SD value measured on the $8^{\text {th }}$ week is quite low (9.6\%) (Figure 2b). The cumulative duration of preparation and observation is very similar for all methods.

\section{Arbuscule richness}

Arbuscule content of roots can be described by two parameters according to the magnified intersections method (AC) and the Trouvelot method (A) (Figure 3a). Arbuscule richness increased fast in the first four weeks of the propagation process, as colonization spread out. From the $4^{\text {th }}$ week until the $10^{\text {th }}$ week it decreased and there is a second peak at the $12^{\text {th }}$ week.

The average variation between the two methods was 5.2. This is barely higher than that of the estimated colonization rate (C; M; HC). Even the crude estimation with three classes for arbusculum richness (A1: low level; A2: moderate level; A3: high level) at the Trouvelot method can approach the AC value quite well. The consistent underestimation of arbuscule richness by the Trouvelot method can be the result of the degraded arbuscules appearing from the $5^{\text {th }}$ week of the growth period.

The duration of the two methods is quite similar (Table III). The observer dependency of $\mathrm{AC}$ was higher than A despite the more subjective evaluation method of Trouvelot (Table III, Figure 3b). 


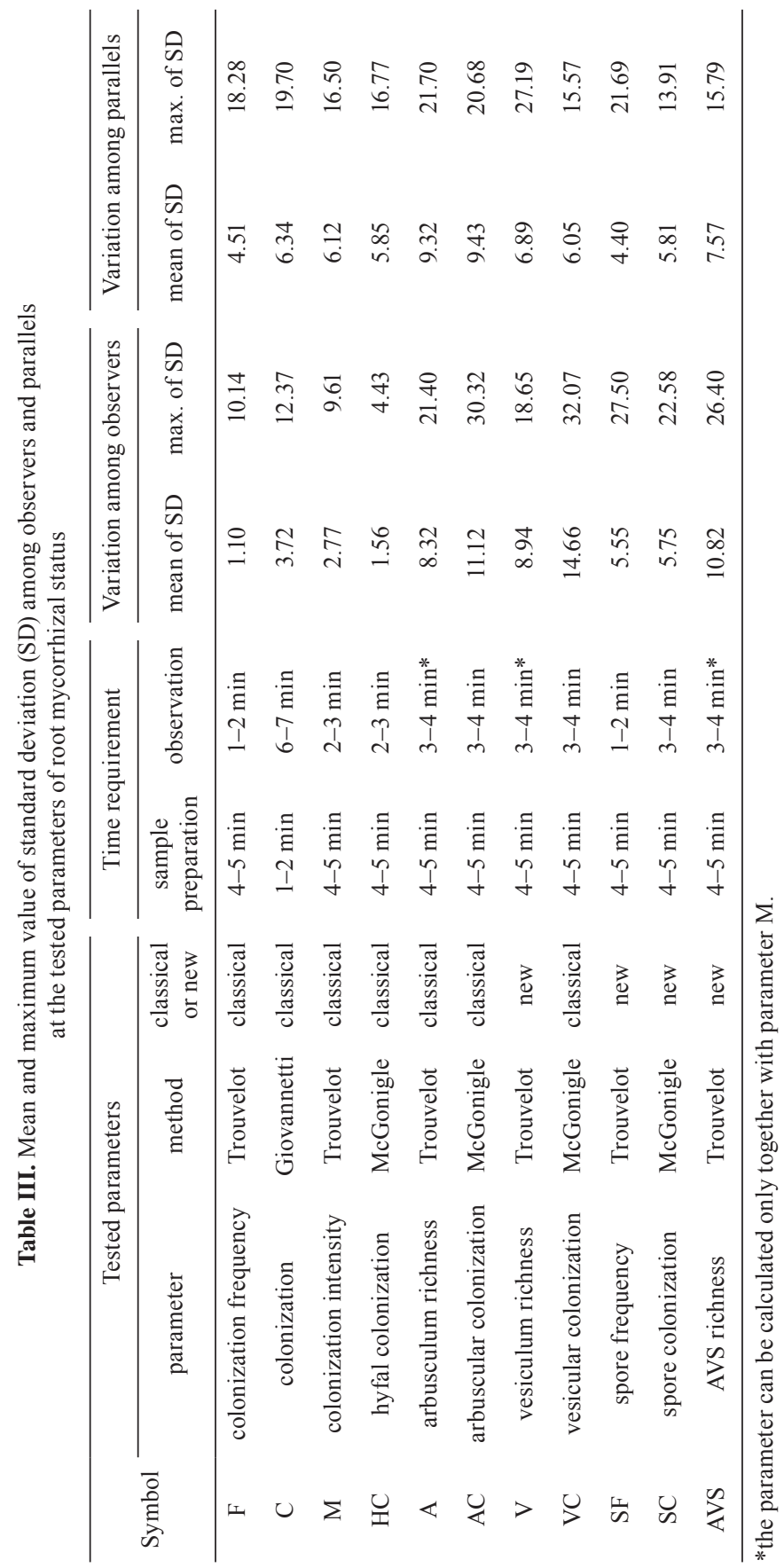



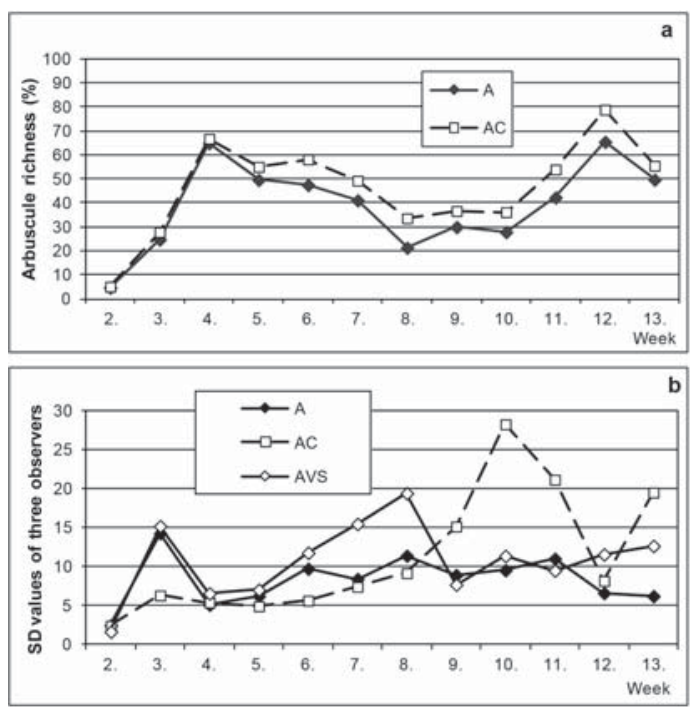

Figure 3. Arbuscule richness and standard deviation of the root system estimated by two different methods during the propagation process, a: mean values of three parallels and three observers, b: standard deviation (SD) among the three observers during the 3 months (AC: according to the magnified intersections method A: according to the five-class system of Trouvelot, AVS: arbusculum, vesiculum and spore content according to the five-class system of Trouvelot)

\section{Vesicule richness}

Two parameters calculated according to the magnified intersections method (VC) and Trouvelot method (V) are shown in Figure 4a. Vesicular colonization, similarly to arbuscule content, increased until the $4^{\text {th }}-5^{\text {th }}$ weeks, but its maximal value is between $30-40 \%$, that is lower than arbuscule richness.

The average variation between the two methods was 2.9. Even the high variances of parallels and observers (Table III), the two parameters do not really differ, and also there is no systematic difference between the two methods. The observer dependency of $\mathrm{VC}$ was higher than $\mathrm{V}$, likewise it was detected in case of comparing A and AC parameters (Table III, Figure 4d).

\section{Spore richness}

Two parameters tested according to the magnified intersections method (SC) and Trouvelot method (SF) are shown on Figure 4b. Spore frequency (SF) is just a crude estimation according to the rate of root segments that contains spore 

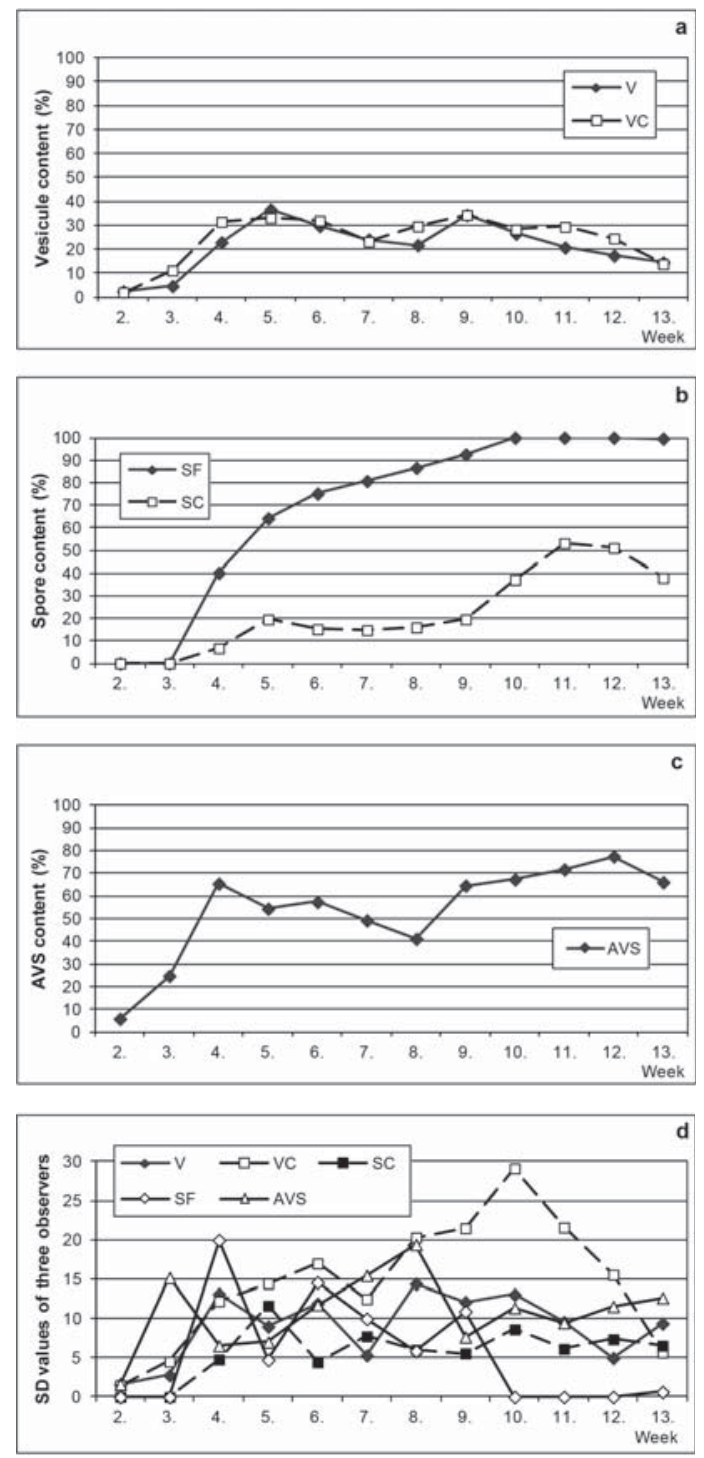

Figure 4. Spore and vesicule content and standard deviation (SD) of the root system estimated by two different methods during the propagation process, a: vesicle content - mean values of three parallels and three observers, b: sporee content - mean values of three parallels and three observers, c: combined appearance of fungal structures in the root system - mean values of three parallels and three observers, $\mathrm{d}$ : standard deviation (SD) among the three observers during the 3 months

(VC: according to the magnified intersections method $\mathrm{V}$ : according to the five-class system of Trouvelot, SC: according to the magnified intersections method,

SF: according to the five-class system of Trouvelot, AVS: arbusculum, vesiculum and spore content according to the five-class system of Trouvelot) 
structure. Spore colonization (SC) represents the rate of root intersections containing spores, expressed in the percentage of the total length.

Both parameters show that spore content reaches its maximal value by the $10^{\text {th }}-12^{\text {th }}$ weeks. The observer dependency of SC and SF are very high during some weeks (Figure 4d), until their amount is low and the presence of spores is not clear in the co-occurrence of vesicles and spores.

\section{Richness of AMF specific structures (AVS)}

AVS is a fast assessment for any fungal structure, except hyphae. Similarly to arbuscule richness (A), two peaks were found during the three months experimental period, a first one in the $4^{\text {th }}$ and a second one in the $12^{\text {th }}$ week (Figure $4 \mathrm{c}$ ). The first peak had a value similar to arbuscule richness (A), the second one was higher.

The observer dependency of AVS value is high (Table III, Figure 4d), one of the highest among parameters, even though there are no difficulties to separate different fungal structures.

\section{Discussion}

Similar to samples of most biological features, standard deviation of parallels can be high in case of AM fungi colonization, too [35]. The sources of the variance could arise either from the sampling process, the sample analysis or the estimation by the observer. In the present experiment, the registered standard deviation (SD) of colonization data is generally not too much; it is usually below $10 \%$ in case of parameters scaled from 0 to 100 percent. There are some sensitive periods during the development of the symbiotic process, when these SD values are above 10, the SD of parallels can even reach 20, and the SD of observers can even increase to 30 .

Numerous publications provide guidelines for destructive sampling processes of different parts of plants, including the sampling of root systems $[36,37]$. However, the majority of manuscripts concentrate only on the methodological approaches of field sampling or on the experimental design of pot allocation. The experiment with parallel samples in one pot can emphasize the importance of sampling method: a root sample containing roots of several plants results a better estimation of colonization values, because there are differences among the roots of the individual plants even growing in the same/very similar microenvironment. Each clover plant has a unique genetic background, which can affect the 
colonization rate $[38,39]$. Root samples should also be collected randomly - samples from the same root system can show surprisingly high variance [40]. In case of a propagation experiment errors can arise due to the uneven distribution of the inoculum (Table I). Root selection from stained root samples is an important and underestimated source of error. The observer may unintentionally select thinner, longer or darker blue/more saturated root segments, generating a consistent error. It is important to choose a minimal 30 pieces of root segments for observation as randomly as possible. However, Rajapakse and Miller [41] recommended that larger roots should be collected separately previous to clearing and staining. To avoid an underestimation of mycorrhizal status, the way of AMF infection and colonization spreading requires fine roots $(<0.5-2.0 \mathrm{~mm}$ in diameter of feeder roots) to be represented sufficiently in the sample. The nuances of the sampling technique depend strongly on the root morphology and architecture of the host plant.

Variation among parallels is the highest in the $3^{\text {rd }}$ and $4^{\text {th }}$ week of propagation, when colonization is not spread in the whole root system. There are also some sensitive periods, when observation is more difficult and observer dependent: (1) the judgment/recognition of degraded arbuscules vary from observer to observer, even at the magnified intersections method, which is thought to be more objective, (2) spores, especially when there are only a few, can easily be counted as vesicle at a fast assessment, (3) different fungal structures can overlap one another, the assessment of the arbuscules is really difficult in the second part of the propagation process.

Selection of the best parameters and optimization of sampling time can maximize the reliability and effectiveness of monitoring and quality control. All tested methods seem to be appropriate for monitoring. The disadvantage of the gridline intersect method that it investigates no fungal structures but the presence of the fungus [42]. It is not recommended to use this method on progressed or final stages of an experiment, when distinction of arbuscules, vesicules and spores can be important. The other two methods look similarly reliable and do not require more effort.

An early check is reasonable during the $2^{\text {nd }}$ or $3^{\text {rd }}$ week. The colonization is quite low at this time, but a fast assessment, e. g. checking only $\mathrm{F} \%$, can confirm that symbiosis exists or hyphal colonization has started. During the $4^{\text {th }}-5^{\text {th }}$ week the colonization rate should raise above $50 \%$, arbuscule richness should have a peak value. Observations are still not disturbed by the overlapping fungal structures in this stage. At this time it is highly recommended to check the colonization and the state of arbuscules with intensity of colonization (M) or hyphal colonization (HC) and arbuscule richness (A) or arbuscular colonization (AC). Arbuscules inside fine roots are the most important symbiotic structures of the 
fungi, which provides the interface for nutrient transportation between the plant and fungi $[43,44]$. Arbuscule content of roots indicates the stages and the functional status of the symbiosis excellently. In the early stages of the symbiosis, high arbuscule richness suggests intense vesicule formation and spore production.

Further sampling and monitoring is recommended at least every fourth week. Beside the summa colonization ( $\mathrm{M}$ or $\mathrm{HC}$ ), these samplings and checks should focus on the AMF propagules: vesicules (V or VC) and spores (SC, SF). Vesicules are the storage structures of AM fungi with high lipid content that can also function as infective propagulum. The spore is one of the most important reproductive structure which usually appears from the $3^{\text {rd }}-4^{\text {th }}$ week [45]. Depending on the AMF species, the size of the spores varies between 20 and $180 \mu \mathrm{m}$ [46]. As spores are usually born with thick wall, separation of small spores from vesicules can be difficult in case of mycorrhiza species that forms spores inside the root, such as Rhizophagus (Glomus) intraradices. The AVS value was tested for avoiding both this error and the problem caused by overlapping fungal structures. The AVS parameter did not come up to our expectations, it was not more reliable than the parameters that estimates fungal structures separately $(\mathrm{A}, \mathrm{AC}$, $\mathrm{V}, \mathrm{VC}, \mathrm{SC}$ ). AVS is strongly observer dependent, standard deviation among observers can even reach $15-20 \%$ in case of percentage scaled values (Figure $4 \mathrm{~d}$ ). This kind of observer dependency can arise because it is difficult to distinguish the arbuscules exactly among the other structures. The appearance of arbuscular structures are not so peculiar, as the spores and vesicules and can be underestimated. Perhaps another combination of parameters concerning vesicles and spores (VS) could avoid these errors and would be suitable for monitoring later stages.

Of course, these recommendations for parameters and time schedule depend on the host plant, the fungus species, the conditions and the aim of the experiment or monitoring the experiment, too. Some mycorrhizal fungi form intraradical spores others do not. The AMF can be Arum-, Paris- or mixed-type depending on the selection of the symbiotic partners [47]. Paris-type mycorrhiza forms coils in the plant roots, which can be an extra parameter in this case [48]. Arbuscule and coil richness indicates the intensity of the metabolism and the functionality of the symbiosis.

In the future the development of methods for colonization measurements should turn to the parameters of mycorrhizal status that are closely related to symbiotic functionality. Techniques based on the detection of AMF structures - i.e. the Giovannetti and Mosse or the McGonigle method - could be improved with the classification of the structures identified. Altough the method of Trouvelot is subjective due to its design, it can be supplemented with the assessment 
of the spore and vesicule richness or with classification as Paris-, Arum- or mixed-type by detecting coils and arbuscules.

The infectivity of indigenous AMF in soils or an inoculum containing root segments can be predicted by the colonization rate of the host. By our investigations, it was the Trouvelot (root scanning) method of all the original and improved procedures that provided the most detailed information. Its results seem to be nearly independent on the personality of the observer except the period of arbuscule degradation and intraradical spore development. Nevertheless, the routine examination should be based on simple decisions about the presence of different AMF structures.

\section{References}

1. Brundrett, M.: Mycorrhizal associations and other means of nutrition of vascular plants: Understanding the global diversity of host plants by resolving conflicting information and developing reliable means of diagnosis. Plant Soil 320(1-2), 37-77 (2009).

2. Smith, S. E., Read, D.: Mycorrhizal Symbiosis, 2nd edn. Academic Press, London (1997).

3. Arora, G. K., Rai, B., Mukerji, K. G., Knudsen, G. R.: Handbook of Applied Mycology, Vol. 1: Soil and Plants. Marcel Dekker Inc, New York, pp. 720 (1991).

4. Turnau, K., Haselwandter, K.: Arbuscular mycorrhizal fungi, an essential component of soil microflora in ecosystem restoration. In Gianinazzi, H., Schüepp, H., Barea, J. M., Haselwandter, K. (eds): Micorrhizal Technology in Agriculture from Genes to Bioproducts. Springer Birkhäuser, Switzerland, pp. 137-149 (2002).

5. Marschner, H.: The soil-root interface (rhizosphere) in relation to mineral nutrition. In Marschner, H. (ed): Mineral Nutrition of Higher Plants. Academic Press, London, pp. 537-594 (1997).

6. Augé, R. M.: Water relations, drought, and vesicular-arbuscular mycorrhizal symbiosis. Mycorrhiza 11, 3-42 (2001).

7. Birhane, E., Sterck, F. J., Fetene, M., Bongers, F., Kuyper, T. W.: Arbuscular mycorrhizal fungi enhance photosynthesis, water use efficiency, and growth of frankincense seedlings under pulsed water availability conditions. Oecologia 169(4), 895-904 (2012).

8. Evelin, H., Kapoor, R., Giri, B.: Arbuscular mycorrhizal fungi in alleviation of salt stress: A review. Ann Bot 104(7), 1263-1280 (2009).

9. Füzy, A., Biró, B., Tóth, T., Hildebrandt, U., Bothe, H.: Drought, but not salinity, determines the apparent effectiveness of halophytes colonized by arbuscular mycorrhizal fungi. J Plant Physiol 165, 1181-1192 (2008).

10. Ruiz-Lozano, J. M., Aroca, R.: Host response to osmotic stresses: Stomatal behaviour and water use efficiency of arbuscular mycorrhizal plants. In Koltai, H., Kapulnik, Y. (eds): Arbuscular Mycorrhizas: Physiology and Function. Springer, Berlin, pp. 239-256 (2010).

11. Giovannetti, M., Sbrana, C.: Meeting a non-host: The behaviour of AM fungi. Mycorrhiza 8, 123-130 (1998).

12. Barea, J. M., Pozo, M. J., Azcón, R., Azcón-Aguilar, C.: Microbial co-operation in the rhizosphere. J Exp Bot 56(417), 1761-1778 (2005). 
13. Gianinazzi, S., Vosatka, M.: Inoculum of arbuscular mycorrhizal fungi for production systems, science meets business. Can J Bot 82(8), 1264-1271 (2004).

14. Vierheilig, H., Schweiger, P., Brundrett, M.: An overview of methods for the detection and observation of arbuscular mycorrhizal fungi in roots. Physiol Plant 125, 393-404 (2005).

15. Cseresnyés, I., Takács, T., Végh, K. R., Anton, A., Rajkai, K.: Electrical impedance and capacitance method: A new approch for detection of functional aspects of arbuscular mycorhrizal colonization in maize. European Journal of Soil Biology 54, 25-31 (2013).

16. Takács, T., Füzy, A., Rajkai, K., Cseresnyés, I.: Investigation of arbuscular mycorrhizal status and functionality by electrical impedance and capacitance measurement: New method for description of AMF functionality. Acta Biologica Szegediensis 58(1), 55-59. (2014).

17. Phillips, J. M., Hayman, D.S.: Improved procedures for clearing roots and staining parasitic and VAM fungi for rapid assessment of infection. Trans Brit Mycol Soc 55, 158-161 (1970).

18. Byrd, D. W., Kirkpatrick, T., Barker, K. R.: An improved technique for clearing and staining plant tissues for the detection of nematodes. J Nematol 15, 142-143 (1983).

19. Kormanik, P. P., McGraw, A. C.: Quantification of vesicular-arbuscular mycorrhiza in plant roots. In Schenck, N. C. (ed): Methods and Principles in Mycorrhizal Research. Am Phytopathol Soc, St Paul, Minn., pp. 37-45 (1982).

20. Brundrett, M.: Estimation of root length and colonization by mycorrhizal fungi. In Brundrett, M., Melville, L., Peterson, L. (eds): Practical Methods in Mycorrhiza Research. Mycologue Publications, Guelph, pp. 51-59 (1994).

21. Grace, C., Stribley, D. P.: A safer procedure for routine staining of vesicular-arbuscular mycorrhizal fungi. Mycol Res 95, 1160-1162 (1991).

22. Ambler, J. M., Young, J. L.: Techniques for determining root length infected by vesiculararbuscular mycorrhizae. Soil Sci Soc Am J 41, 551-556 (1977).

23. Biermann, B., Linderman, R. G.: Quantifying vesicular arbuscular mycorrhizae: A proposed method towards standardization. New Phytol 87, 63-67 (1981).

24. Brundrett, M. C., Piché, Y., Peterson, R. L.: A new method for observing the morphology of vesicular-arbuscular mycorrhizae. Can J Bot 62, 2128-2134 (1984).

25. Giovannetti, M., Mosse, B.: An evaluation of techniques for measuring vesicular-arbuscular mycorrhizal infection in roots. New Phytol 84, 489-500 (1980).

26. Hayman, D. S., Azcón, R., Barea, J. M.: Vesicular-arbuscular mycorrhizae in Southern Spain: Its distribution in crops growing in soil of different fertility. Phytopathol Mediterr 15, 1-6 (1976).

27. Li, A. R., Guan, K. Y.: Mycorrhizal and dark septate endophytic fungi of Pedicularis species from northwest of Yunnan Province, China. Mycorrhiza 17, 103-109 (2007).

28. McGonigle, T. P., Miller, M. H., Evans, D. G., Fairchild, G. L., Swan, J. A.: A new method which gives an objective measure of colonization of roots by vesicular-arbuscular mycorrhizal fungi. New Phytol 115, 495-501 (1990).

29. Morandi, D., Prado, E., Segan, M., Duc, G.: Characterisation of new symbiotic Medicago truncatula (Gaertn.) mutants, and phenotypic or genotypic complementary information on previously described mutants. Mycorrhiza 15, 283-289 (2005).

30. Newman, E. I.: A method of estimating the total length of root in a sample. J Appl Ecol 3, 139-145 (1966).

31. Plenchette, C., Morel, C.: External phosphorus requirement of mycorrhizal and nonmycorrhizal barley and soybean plants. Biol Fertil Soils 21, 303-308 (1996). 
32. Tennant, D.: A test of modified line intersect method of estimating root length. J Ecol 63, 995-1001 (1975).

33. Trouvelot, A., Kough, J. L., Gianinazzi-Pearson, V.: Mesure du taux de mycorhization VA d'un systeme radiculaire. Recherche de methodes d'estimation ayant une significantion fonctionnelle. In Gianinazzi-Pearson, V., Gianinazzi, S. (eds): Physiological and Genetic Aspects of Mycorrhizae. INRA, Paris, pp. 217-221 (1986).

34. Öpik, M., Moora, M., Liira, J., Zobel, M.: Composition of root-colonizing arbuscular mycorrhizal fungal communities in different ecosystems around the globe. J Ecol 94, 778-790 (2006).

35. Kliromonos, J. N., Rillig, M. C., Allen, M. F.: Designing belowground field experiments with the help of semi-variance and power analyses. Appl Soil Ecol 12, 227-238 (1999).

36. Johnson, J. M. F., Morgan, J.: Plant sampling guidelines. In Follett, R. F. (ed.): Sampling Protocols. USDA, pp. 1-10 (2010).

37. Taylor, H. M.: Methods of studying root systems in the field. Hort Sci 21, 952-956 (1986).

38. Estaún, V., Calvet, C., Camprubí, A.: Effect of differences among crop species and cultivars on the arbuscular mycorrhizal symbiosis. In Koltai, H., Kapulnik, Y. (eds): Arbuscular Mycorrhizas: Physiology and Function. Springer, Netherlands, pp. 279-295 (2010).

39. Smith, K. P. and Goodman, R. M.: Host variation for interactions with beneficial plantassociated microbes. Annu Rev Phytopathol 37, 473-491 (1999).

40. Reich, L., Barnard, J.: Sampling strategies for mycorrhizal research. New Phytol 98, 475479 (1984).

41. Rajapakse, S., Miller, J. C. J.: Methods for studying vesicular-arbuscular mycorrhizal root colonization and related root physical properties. In Norris, J. R., Read, D. J., Varma, A. K., (eds): Methods in Microbiology. Volume 24: Techniques for the Study of Mycorrhiza. Academic Press, London, pp. 301-316 (1992).

42. Utobo, E. B., Ogbodo, E. N., Nwogbaga, A. C.: Techniques for extraction and quantification of arbuscular mycorrgizal fungi. Libyan Agric Res Cent J Int 2, 68-78 (2011).

43. Bonfante-Fasolo, P.: Anatomy and morphology of VA mycorrhizae. In Powell, C. L., Bagyaraj, D. J. (eds): VA Mycorrhiza. CRC Press, Boca Raton, pp. 5-33 (1984).

44. Cox, G., Tinker, P. B.: Translocation and transfer of nutrients in vesicular-arbuscular mycorrhizas. I. The arbuscule and phophosrus transfer: A quantitative ultratructural study. New Phytol 77, 371-378 (1976).

45. Escandari, A., Danesh, Y. R.: Study on life cycle of arbuscular mycorrhizal fungus Glomus intraradices using in vitro culturing technique. J Phytol 2, 69-75 (2010).

46. Giovannetti, M.: Spore germination and pre-symbiotic mycelia growth. In Kapulnik, Y., Douds, D. D. (eds): Arbuscular Mycorrhizas: Physiology and Function. Kluwer Academic Publishers, Dordrecht, pp. 47-68 (2000).

47. Dickson, S.: The Arum-Paris continuum of mycorrhizal symbioses. New Phytol 163, 187-200 (2004).

48. Kubota, M., McGonigle, T. P., Hyakumachi, M.: Co-occurrence of Arum- and Paris-type morphologies of arbuscular mycorrhizae in cucumber and tomato. Mycorrhiza 15, 73-77 (2005). 